\title{
New Technologies in Professional Learning Networks
}

\author{
Lauren A. Menard, Ed.D. \\ Northwestern State University \\ menardl@nsula.edu
}

\author{
Diane F. Olivier, Ph.D. \\ University of Louisiana at Lafayette \\ dolivier@louisiana.edu
}

\begin{abstract}
Web-based Professional Learning Networks (PLN) expand the collective knowledge base and improve project coordination and integration. Web-based networks hold potential for improving service-learning by (a) broadening participation and reaping the benefits of collective knowledge; (b) encouraging engagement, discussion, and collaboration through asynchronous communication; (c) improving the sharing, storage, organization, and retrieval of project information and materials; (d) keeping all members informed through efficient emailing notifications and posts; (e) distributing certificates and badges as incentives; and (f) surveying members for feedback and evaluation to guide improvement. The present article illustrates practical applications of PLN technologies and describes a free social learning platform.
\end{abstract}

Index terms: Communication, e-service-learning, professional learning networks, servicelearning, technologies

\section{NEW TECHNOLOGIES IN PROFESSIONAL LEARNING NETWORKS}

Collective communication, collaboration, and networking are at the center of service-learning. There are practical considerations and organizational nuts and bolts with every project, such as costs and communication among members. Technology can enhance collaboration and information sharing within learning environments and among learning communities. Many project coordinators, such as college professors, are likely to have institutional access to platforms with features they may not realize are useful for developing and facilitating online service-learning in ways similar to the organization of online coursework. Other individuals instrumental to developing service-learning projects, such as privately-based community organizers, may be unaware of a social learning network that is freely available on the World Wide Web.

A purpose of the current review is to inform readers about Professional Learning Networks (PLN) technologies and encourage applications that improve the organization and management of their service- learning projects. Background information on learning networks and servicelearning is followed by discussions of e-service-learning and features of the free social learning platform Edmodo ${ }^{\odot}$. Several innovative applications of web-based learning networks are described.

\section{LEARNING NETWORKS AND SERVICE LEARNING}

Professional Learning Communities (PLC) are organizational structures that create nurturing environments for the learning and growth of members and achievement of common goals. According to Hord" ${ }^{1}$, "Learning is not an add-on to the role of the professional. It is a habitual 
activity where the group learns how to learn together continuously." ${ }^{\text {(40) }}$ Leadership is shared in learning communities, and accountability for reaching goals is a collective responsibility. Peer accountability, rather than administrative directives, inspires commitment to participation and learning in learning networks. ${ }^{2}$ The PLC framework provides an organizational package for communication and collaboration that holds the group mission central and, thereby, expands capacity in achieving goals. The purpose of professional learning communities or networks is commitment to the established mission and attainment of common goals. Professional Learning Communities offer supportive structure for the creating and sharing of an overall vision, ideas, and personal practices. With an intentional focus on collective learning for the purpose of developing and applying new knowledge and skills, these supportive networks build collegial relationships. Advancing the learning and communication gathering of group members broadens their contributions to collective effort. Thus, learning communities strengthen the organizational structure supporting professional development and staff collaboration. ${ }^{3}$

The concept of PLC is rooted in the field of education. ${ }^{4}$ According to Flanigan", "As budget cuts continue to limit district-level training opportunities, PLNS take an organic, grassroots approach to professional development. Administrators and teachers say such networks reduce isolation, promote autonomy, and provide inspiration by offering access to support and information". (6) When teachers organize in learning groups, such as $4^{\text {th }}$ Grade Science or European History, they serve important school purposes. ${ }^{3}$ The school's larger structure ensures organizational goals are being pursued and staff effort is aligned with the common goal of student learning. ${ }^{2}$ Learning communities reduce staff isolation; increase commitment to and vigor in working on common goals; develop new knowledge and strengthen understandings; and are associated with lower absenteeism, greater satisfaction, and higher staff morale. ${ }^{2}$ The difference between traditional staff collaboration and learning networks is that student learning is the intended purpose of collaboration in both PLC and PLN. This focus on, or enhancement of, professional learning is the avenue to improved student outcomes. Learning networks for teachers are associated with the following benefits for students: lowered dropout and absenteeism, increased learning and larger academic growth, and reduced income and racial gaps in educational achievement. ${ }^{3}$

A sense of community and collectiveness is fundamental to both the PLN framework and the mission of service-learning. Learning is a process constructed from information and experiences within a social context. ${ }^{1}$ Whether it be engaging the elderly, preparing the community for emergencies, assisting the mentally challenged, or forging business and community partnerships, students have a lot to learn from service-learning. With servicelearning projects, the needs of the community are better understood and supported, and students recognize connections between service and their academic work. ${ }^{6}$ Realizing these connections can enrich meaning in students' personal lives.

Community engagement and a mission of service for the common good may never be more needed than it is today. According to Putnam ${ }^{7}$, at the end of the $21^{\text {st }}$ century Americans were "growing ever less connected with one another and with collective life. We voted less, joined less, gave less, trusted less, invested less time in public affairs, and engaged less with our friends, our neighbors, and even our families". (para. 1) As Americans participated and engaged with those around them less frequently, their collective we diminished. ${ }^{7}$ Service-learning projects offer opportunities to strengthen neighborhoods and communities and rebuild our we. 


\section{E-SERVICE LEARNING}

E-service-learning is service-learning that is conducted through an online platform. Web-based learning can increase participation, enlarge the collective knowledge base, and compound individual and community benefits by freeing "service-learning from place-based access or geographical constraints". ${ }^{8(126)}$ Existing literature on e-service-learning is embryonic and the development of e-service models is of growing interest. ${ }^{6,8,9}$

In the article E-Service-Learning: The Evolution of Service-Learning to Engage a Growing Online Student Population, e-service-learning is defined as a service-learning course where both instructional and service learning components are delivered online. ${ }^{8}$ According to Waldner, McGorry, and Widener ${ }^{8}$, "e-service-learning is not a mere pedagogical curiosity; rather, it is a key to the future of service-learning" ${ }^{(124)}$ E-service-learning stems from the genre of distance learning, that is, providing integrated, constructive, multidisciplinary learning experiences that have real-world applications through the World Wide Web. ${ }^{6.8}$ Education, service-learning, and online networks are conceptually linked. The Center for Digital Civic Engagement describes service-learning in online courses as a hybrid of the pedagogies of online teaching and civic and community engagement. ${ }^{10}$ Online learning and service-learning both benefit from e-servicelearning. Professors who master the intersection of pedagogies, "have more effective expertise than those whose excellence lies strictly in the content discipline, strictly in the pedagogy (e.g., service-learning), or strictly in the technology (e.g., online learning techniques)". (128) Online platforms promote student learning in service-learning through improved access, participation, civic engagement, and learning outcomes. ${ }^{8}$

The tools of e-service-learning can be applied to service-learning projects, not only servicelearning courses. In Utilizing Mobile Devices and Web-based Tools to Enhance Service Learning and Civic Engagement, King observes the power of the social and the collective are difficult to ignore within the landscape of today's digital technologies. ${ }^{11}$ Informing and visually engaging YouTube videos are one example of how today's technologies facilitate servicelearning. ${ }^{11}$ From Cambodian overseas projects to service-learning abroad in Haiti, a YouTube search for the term service-learning yielded 3,960,000 results in about a second. ${ }^{12}$ Apps can also save time and assist with the logistics of service-learning projects. ${ }^{11}$ Trinity Lutheran College's SALLT Service Learning App is a free app available from the Apple App Store that helps organize and support youth mission trips. ${ }^{13}$ King identified the following additional interesting technologies with applications for service-learning projects: (a) Wiggio, a tool for collaborating online; (b) Clickfix, a service for citizens to receive government and media alerts in various locations; and (c) Animoto, a program that can create and share extraordinary videos from service-learning photos. ${ }^{11}$ Features of a free web-based social learning platform and practical applications that highlight the potential of web-based learning networks to facilitate servicelearning are discussed in the following section.

\section{A FREE ONLINE SOCIAL LEARNING NETWORK: EDMODO ${ }^{\odot}$}

Edmodo $^{\odot}$ is a thriving learning network now used by 42,082,691 teachers, students, and parents. ${ }^{14}$ It is the world's largest social learning community. According to Rivero ${ }^{15}$, "Two school district web pros put their heads together back in 2008 - a million users later, it seems like a good idea". ${ }^{(14)}$ Developers expected 200 attendees for the first Edmodocon virtual conference in 2011, but over 2,000 educators participated. ${ }^{5}$ Edmodo ${ }^{\odot}$ feels similar to the social 
network Facebook ${ }^{\odot}$, but it is a community focused on purposeful learning among professionals. The Edmodo ${ }^{\odot}$ companion app increases mobility and accessibility. The iTunes ${ }^{\Theta}$ description of the award winning app reads, "Edmodo makes a teacher's daily life easier by providing a safe and easy way for teachers and students to engage and collaborate for free, anytime, anywhere." ${ }^{(\mathbb{N} 11)}$ Accounts can be created for classrooms, school districts, or communities. A screen shot of the Edmodo $^{\odot}$ community area is shown on Figure 1 . To join or create a community, members sign up, gain a group code, and invite others to join.

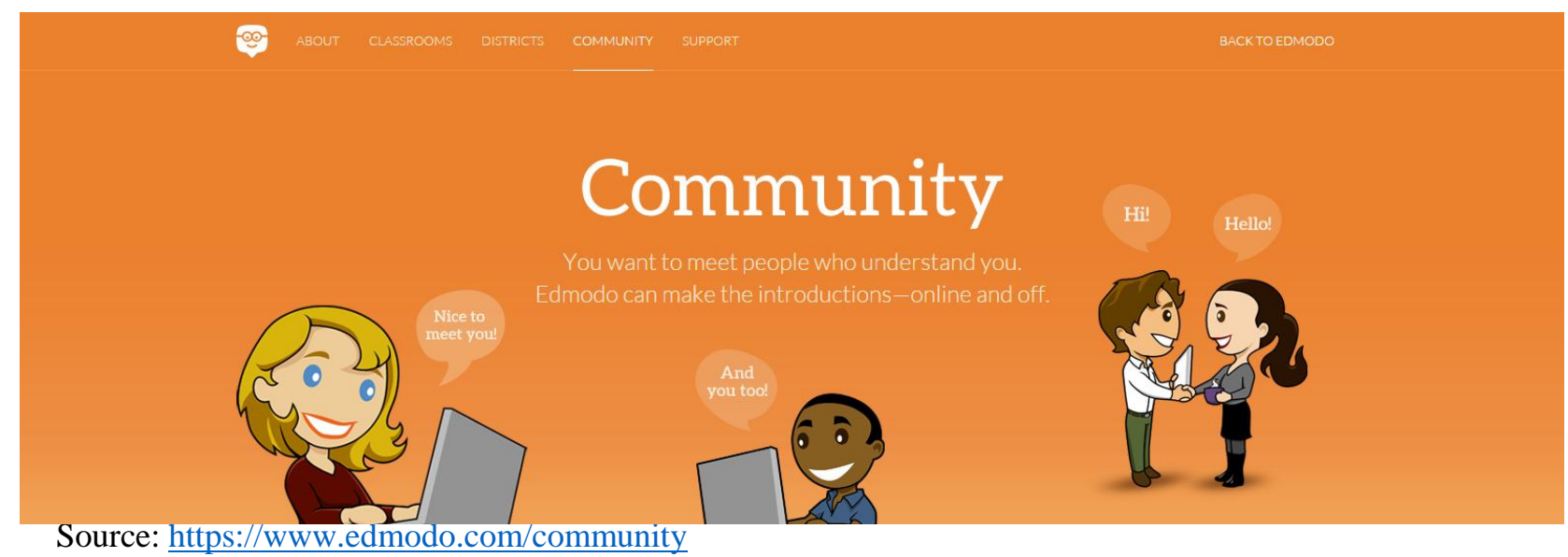

FIGURE 1

JOIN THE SOCIAL LEARNING COMMUNITY

Edmodo $^{\odot}$ is widely used as a social learning network by a growing number of classroom teachers and school districts. According to Flanigan, "Teachers in Nevada's 310,000-student Clark County school district, which includes Las Vegas, have been using Edmodo as an instructional tool for two years; students can be given a secure, password-protected username to share homework assignments, conversations, and class notes". ${ }^{5(510)}$ The Katy Texas School District also partnered with $\operatorname{Edmodo}^{\odot}$ to advance social learning networking among teachers, students and administrators. ${ }^{17}$ A district technology specialist from the Katy school district observed, "What's the first thing students do when they leave school?"... They whip out their phone". ${ }^{2(6)}$ Educators wanted to speak the native digital language of students. The Edmodo ${ }^{\Theta}$ app allows the teacher to communicate with students "in 140-character alerts about upcoming assignments or tests that mimic the tweets and texts they receive from friends". ${ }^{17(6)}$ Feedback has been positive. An eighth-grade teacher at a Katy middle school observed "Edmodo has revolutionized her classroom in terms of student engagement and time saved. By the time she logs on to answer student questions, other students have already answered them." Classroom teachers may have been using Facebook, Twitter, emails, wikis, and blogs to interact and communicate, but $\mathrm{Edmodo}^{\odot}$ offers a reputable educational platform with more features that is designated specifically for social learning.

The Edmodo ${ }^{\odot}$ community is closed and private. ${ }^{18}$ Only those members who are given a code by the site manager can access the group. ${ }^{18}$ With district accounts, there may be greater security that participation is monitored for compliance with district internet use policies. Other safeguards can be enabled, such as only allowing students to send messages to the teacher or group. ${ }^{17}$ 
Edmodo $^{\odot}$ was determined secure enough that the Katy district revised its acceptable use policy for devices so the social learning app could be used at school under teacher supervision. ${ }^{17}$

Edmodo $^{\odot}$ is marketed as Where Learning Happens and is specifically designated as a K-12 learning network. The Edmodo ${ }^{\odot}$ Special Education community has 19,721 followers and the Professional Development community has 36, 875 followers, for examples. The wide-ranging span of community topics, large number of participants, access to resources, and platform features, however, translate to a viable mode of participation and communication for a diversity of projects, including service-learning. A quick search through Edmodo ${ }^{\odot}$ content yielded the communities of Public Service Announcements and Community Services for the term servicelearning. ${ }^{14}$ Communities within Public Service Announcements include a variety of specific content, such as Drug Awareness, Cyberbullying, and Families with Purpose. The Community Involvement Edmodo ${ }^{\circledR}$ community includes groups such as the Latino Role Model Conference and Napa County's Children \& Weight Coalition. Various applications of Edmodo ${ }^{\odot}$ are highlighted in the following sections.

\section{In the Classroom}

Edmodo ${ }^{\odot}$ was used in a fourth grade classroom in a small Kansas town to facilitate student collaboration within and beyond the school house walls. ${ }^{18}$ According to Dobler, "By skillful use of the educational website Edmodo, www.edmodo.com, Jan and her students have raised the roof of their classroom, flattened the walls, and brought voices from communities far and wide into their daily learning". ${ }^{18}$ (12) More than two thousand students worldwide participated with Ms. Jan's students in a Global Read Aloud of Tuck Everlasting (Natalie Babbitt) and Flat Stanley (Jeff Brown) by reading the same books in their own classrooms and blogging and video conferencing under their teacher's direction. Edmodo@ was utilized again when the classroom was merged with a Louisiana classroom for a guest speaker presentation. An Edmodo ${ }^{(}$ backchannel facilitated student discussions during the presentation, and a transcript of student comments was given to the speaker after the presentation. Other classroom uses of Edmodo ${ }^{(}$ have included the posting of students' work and linking to video clips, images, or other information that enhance learning connections. ${ }^{18}$

\section{Special Education Community}

Edmodo $^{\circledR}$ was used by one of the authors to disseminate special education curriculum information. Louisiana had recently embarked on Common Core State Standards and Compass standards-based reform initiatives and facilitating accurate, timely, and consistent information to all special education personnel throughout the rural district was a challenge. A Special Education Edmodo $^{\odot}$ community was created to be used as an online PLN. Advantages of using Edmodo ${ }^{\odot}$ over traditional embedded teacher support and professional development included the following: (a) information could be reviewed by teachers whenever convenient, (b) documents were in one place and able to be printed when, or if, needed, (c) questions and comments could be postedmaking use of collective knowledge through learning and application, and (d) new procedures, revisions, and information were able to be uploaded and disseminated districtwide with consistency and minimal effort. The Edmodo ${ }^{\odot}$ social learning group made use of collective knowledge and improved collaborative efforts - the curriculum coordinator informed service providers, who shared information with the coordinator, who in turn, improved information offered to service providers. Staff faced an abundance of new information at the beginning of the year, and procedures differed, to some degree, by role (e.g., teacher, speech pathologist). 
Distributing hard copies of agendas and handouts during visits or at meetings are traditional procedures of staff development. A better alternative, as shown on Figure 2, was uploading files in a group library.

\section{Library Items}

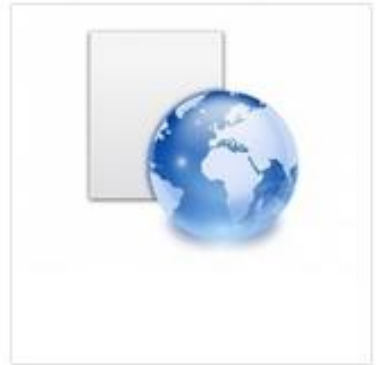

Sample SPEd ELA SLT

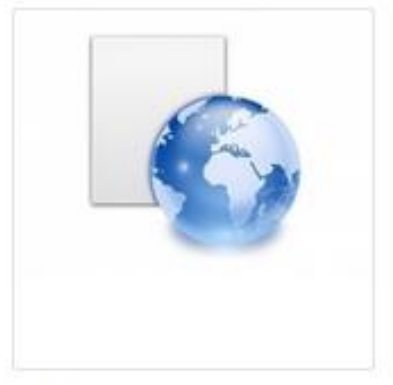

Common Assessments

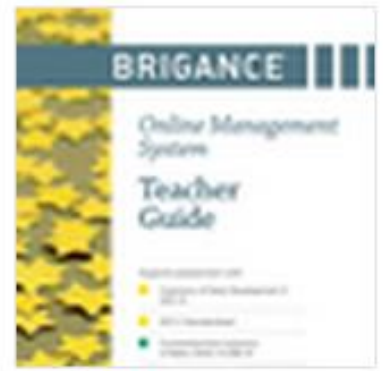

\section{Brigance Management Teacher Guide.pdf}

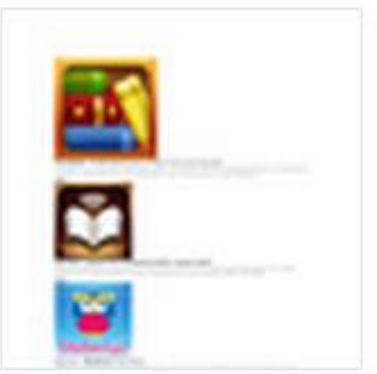

Educational Apps 1 .doc
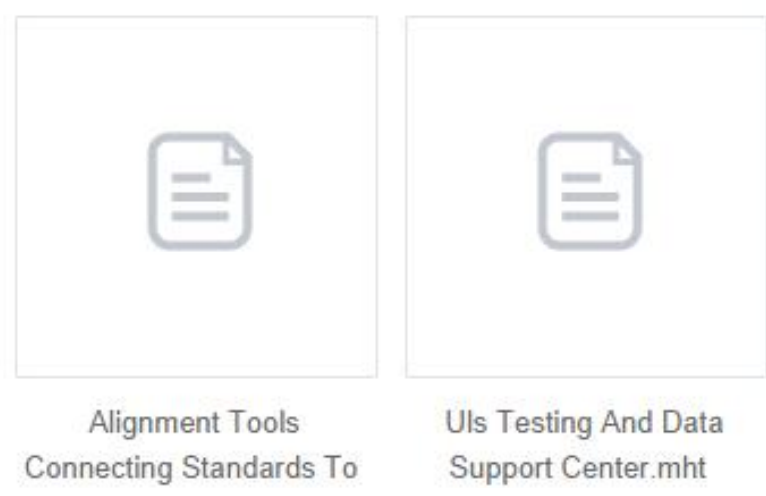

FIGURE 2

A SAMPLE GROUP LIBRARY

The create a folder feature of Edmodo $\odot$ was especially convenient for providing efficient access to a variety of files, including a state powerpoint on writing Student Learning Targets, a Brigance Management Teachers Guide, a link to Easycbm, and Unique Learning Systems' Common Core Alignment documents. Files could be substantial in cases of scoring guides and curriculum/standards alignment documents. Storing the files digitally allowed service providers to print only the information that pertained to them. A significant benefit was that there was no risk of misplacing important papers on crowded desks and no need to spend time searching the web for needed information when files were stored together in content folders in the group's Edmodo $^{\circledR}$ library. The library of electronic files allowed service providers to view and review a variety of information and examples before making decisions. The efficient email notification feature ensured all team members were immediately informed when new files were uploaded.

Distribution of the same information to everyone at the same time promotes compliance. Consistency across schools can be lacking with district level administration because supervisors 
cannot go to all schools at the same time. This is particularly true in district where schools may be two hours away from each other. If new resources became available by the state or a team member developed a more efficient procedure, the information can be quickly shared on Edmodo $^{\Theta}$ with all staff members. This feature may be very beneficial to service-learning projects when timely information to members and their families is of utmost interest.

\section{Online Course}

Like many other states, Louisiana offers statewide professional development. ${ }^{19}$ The author searched for an informative and convenient professional development opportunity in 2012. The course Apps to Build Literacy was offered online to Louisiana teachers by the Northeast Assistive Technology Center. Offering professional development statewide, with one presentation, on such a popular topic as the use of ipad apps in literacy instruction, held many advantages. Cost was the most obvious benefit. There were no travel expenses for presenter or participants. Expenses were further reduced by using the free, online Edmodo ${ }^{\odot}$ platform for course delivery. The convenience of asynchronous participation was a main advantage for participants. Busy teachers and parents could participate and gain professional learning credit by logging in after school, after soccer practice, or whenever convenient during the week. Most teachers would likely agree asynchronous participation is much better than reporting for after school or Saturday morning professional development. Online delivery through Edmodo ${ }^{\odot}$ allowed about 20 teachers to participate in the week-long course. There was no formal follow-up to evaluate student benefits or how many teachers transferred knowledge gained into classroom practices. First-hand experience and observations validate the advantages of storing group files electronically. Too often quality information is put aside following professional development or presentations. Edmodo ${ }^{\odot}$ facilitates the development of learning libraries- a place to go when last year's professional development is needed for today's client or project.

\section{Service-Learning Network}

Assigning groups in Edmodo ${ }^{\odot}$ is a helpful feature A sample service-learning Edmodo ${ }^{\odot}$ site was created for demonstration at the 2013 University of Louisiana Monroe Academic Summit Service. The following Selected conference presentation topics were used as groups:

- Actuarial Preparatory Work for High School Students

- Aviation Mock Disaster

- Building Service-Learning into Your Textbooks: Publishing, Custom Publishing, and Creating Service-Learning Guides

- Community Educational Support of Clients with Mental Illness at Second Beginnings

- Developing Strategic Marketing Plans for Community Businesses

- Engaging the Aging: Closing the 40-year Age Gap in a Gerontology Course through Service-Learning

- Examples of Service-Learning for Professional Block Students at a University in Northeast Louisiana

- The Safety Hazards of Lead Paint in the Natchitoches Historic District

Assigning groups can be used in many ways, such as assigning different classrooms or grade levels their own group. There are numerous applications for online service-learning networks, 
such as the uploading of maps, schedules, supply lists, and helpful reminders. Additional features of Edmodo ${ }^{(0)}$ were demonstrated at the conference. Three virtual badges (Bronze: 10 Hours; Silver: 25 Hours; and Gold: 50 Hours) were created for the service-learning community. Badges can be distributed by the site manager to keep members motivated towards goals. Quizzes and grades can also be given, and members can post to discussion boards. Edmodo ${ }^{\odot}$ can serve as a community board or communication tree to inform members and other stakeholders of activities. The polling feature is an efficient way to survey for program evaluation and feedback and gain data to guide improvements. Service-learning certificates, such as the sample certificate shown in Figure 3, can be distributed electronically through the Edmodo ${ }^{\odot}$. If a high school student, for example, misplaces a needed service-learning certificate, the certificate is easily reprinted when the site member has access to an electronic copy and has records showing when the certificate was awarded.

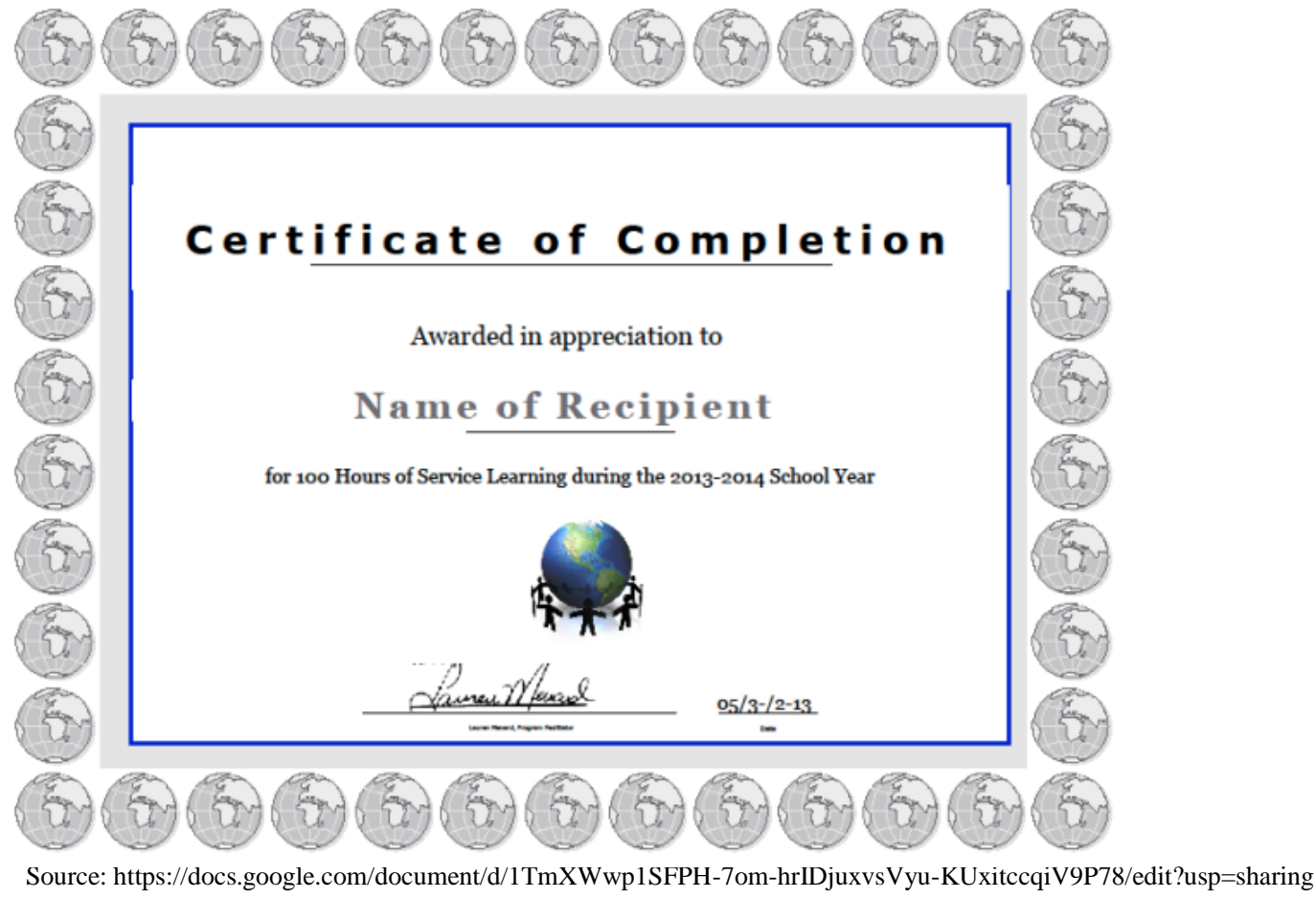

FIGURE 3

SAMPLE SERVICE LEARNING CERTIFICATE

\section{DISCUSSION}

Project managers are encouraged to find ways of applying network technologies that assist them in organizing and managing their own service-learning projects. The present review may inspire college professors to include a service-learning component in their online courses or motivate service-learning project coordinators to upload electronic files, such as maps and requirements, and make them more readily accessible to group members. Using apps for alerts and to create videos are other practical service-learning applications of technologies. The current review described readily available and free of charge features of the social learning network Edmodo ${ }^{(}$ that can be utilized to develop and facilitate e-service-learning projects. Online learning 
networks utilize the PLC concept and offer supportive conditions that strengthen communication, purposeful learning, collective knowledge, and a sense of community. A wealth of collaboration and ideas exchange on a wide range of topics is available on Edmodo ${ }^{\odot}$. Groups may prefer to harness their own collective knowledge and create a specific web-based learning network. Wherever an internet connection and computer (or mobile devices) are available, a learning network can be established.

\section{Acknowledgments}

A special thanks to Dr. Morris Coats, Nicholls State University, for his assistance in preparing a proposal from a previous version of this article that was presented at the 2013 University of Louisiana Academic Summit.

\section{REFERENCES}

1. Hord SM. Professional learning communities. Journal of Staff Development. 2009; 30(1): 4043.

2. Leaning Forward. Standards for professional learning (Shirley Hord). 2014. http://learningforward.org/standards/learning-communities\#.VDBuBfldVOi

3. Hord SM. Professional learning communities: What are they and why are they important? Issues About Change. 1997; 6(1): 1-8

4. Hord SM., Roussin, JL., \& Sommers, WA. Guiding Professional Learning Communities: Inspiration, Challenge, Surprise, and Meaning. Thousand Oaks, Calif: Corwin; 2010.

5. Flanigan RL. Networking professionals: Professional learning networks take an organic, grassroots approach. Education Week. 2011; 31(9): 510-512.

6. Strait J., \& Sauer T. Constructing experiential learning for online courses: The birth of eService. 2004. Educause Quarterly, 27(1): 62-65.

7. Putnam RD. Bowling together: The United State of America. The American Prospect. 2002. 13: 20-22. http://prospect.org/article/bowling-together-0

8. Waldner LS, McGorry SY, \& Widener MC. E-service-learning: The evolution of servicelearning to engage a growing online student population. Journal of Higher Education Outreach and Engagement. 2012; 16(2): 123-150.

9. Crabill SL, \& Dan WB. Community engagement 2.0?: Dialogues on the future of the civic in the disrupted university. New York: Palgrave Macmillan; 2014.

10. Minnesota Campus Compact. Service learning in online courses: Exploring opportunities [slideshare].2010. http://www.slideshare.net/mncampuscompact/servicelearning-online

11. King SS. E-engagement tools: Utilizing mobile devices and web-based tools to enhance service learning and civic engagement [slideshare]. 2012. http://www.slideshare.net/ohiocampuscompact/e-engagement-tools-for-servicelearning

12. Youtube. Service-learning. nd. https://www.youtube.com/results?search_query=service+learning\&page=5

13. Trinity Lutheran College. SALLT Service Learning App [Apple app]. 2014. https://itunes.apple.com/us/app/sallt-service-learning-app/id623251434? $\mathrm{mt}=8$

14. Edmodo. Where learning happens. 2014. http://www.edmodo.com/

15. Rivero V. We're talking social media in education. Internet@School. 2011; 18(3): 12-15. http://www.internetatschools.com/Articles/ReadArticle.aspx?ArticleID=75182 
16. Apple Inc. iTunes preview: Edmodo. 2013. https://itunes.apple.com/us/app/edmodo/id378352300?mt=8

17. Electronic Education Report. Districts Look for Facebook-Like Learning. November 1, 2010; 17 (21):1-6.

18. Dobler E. Flattening classroom walls: Edmodo takes teaching and learning across the globe. Reading Today. 2012; 29(4): 12-13. http://www.dentonisd.org/cms/lib/TX21000245/Centricity/Domain/3150/Flattening\%20Class room $\% 20 \mathrm{Walls.pdf}$

19. Louisiana Department of Education. Online registration system (Coursewhere). https://www.solutionwhere.com/ldoe/cw/main.asp 